\title{
The Level of Optimism and Pessimism and its Relationship to the Quality of Life in Patients with Renal Failure in the Government and Private Hospitals in Irbid
}

\author{
Fatima N. Al Jarrah ${ }^{1}$, Dr. Falastine R. Hamdan ${ }^{2}$, Dr. Munther R. Hamdan ${ }^{3}$, Alaa Fraihat ${ }^{4} \&$ Dr. Abed Alnaser A. \\ Alazzam $^{5}$ \\ ${ }^{1}$ Instructor, Psychological counseling, Irbid University College, Al- Balqa' Applied University, Jordan \\ ${ }^{2}$ Assistant Professor, Irbid University College, Al- Balqa' Applied University, Jordan \\ ${ }^{3}$ Internal medicine and nephrology, Princess Basma Hospital, Ministry of Health, Jordan \\ ${ }^{4}$ Department of Associate Nursing, Al-Balqa Applied University, Jordan \\ ${ }^{5}$ Assistant Professor, Irbid University College, Al- Balqa' Applied University, Jordan \\ Correspondence: Fatima N. Al Jarrah, Instructor, Psychological counseling, Irbid University College, Jordan
}

Received: January 5, 2019

Accepted: March 3, 2019

Online Published: March 11, 2019

doi:10.5539/ijps.v11n2p9

URL: https://doi.org/10.5539/ijps.v11n2p9

\begin{abstract}
The aim of this study was to detect the level of optimism and pessimism and its relation to the quality of life in patients with renal failure in the government and private hospitals in Irbid in light of the variables: gender, age, duration of disease and educational level of patients, the sample of the study consisted of (93) patients with kidney failure, who were randomly selected from the study population. The researchers used optimism and pessimism scale and the quality of life scales, their validity and reliability were verified. Results of the study showed that the means for optimism scale ranged between (3.602-3.075) with a medium degree, and the means for pessimism scale ranged between (4.086-3.118) with a high and medium degree, while the means for quality of life scale ranged between (4.054-2.957) with a high and medium degree. Results also showed the existence of a correlation between the level of optimism and the level of quality of life and this relationship is a moderate relationship, and a lack of correlation between level of optimism and level of pessimism and level of pessimism and quality of life. There are no statistically significant differences at the level of significance $(0.05)$ in the patients' responses on the optimism, pessimism scales according to (gender, family income, medical insurance and origin).
\end{abstract}

Keywords: optimism, pessimism, quality of life, patients with renal failure, government hospitals, private hospitals

\section{Introduction}

Psychologists look at the subject of optimism and pessimism with great interest because of their significant impact on human behavior and a clear reflection on the psychological and physical state of individuals; most theories have confirmed the correlation of optimism with happiness, perseverance and positive outlook on life. Optimism prompts the individual to feel happy, which drives him to the desire to live with desire, perseverance and high ambition, because he expects the odds of success as optimistic individuals believe that their success in their tasks depends to a large extent on their sense of optimism, on the basis of "Hope for the best and you shall find it." The individual cannot progress and succeed if he does not have enough optimism (Abdul Karim, 2010). As for the individual's sense of pessimism and his failure to satisfy his needs, he feels despair, loss of hope and anticipation of failure and hesitation.

Optimism and pessimism have a profound impact on human behavior in terms of their reflection on the psychological and emotional state of and his optimistic and pessimistic view of the present and the future (Nabil and Shu'ail, 2014). Psychological studies of optimism and pessimism are among the recent studies that have begun to take place during the last three decades the first book of contributions in the crystallization of this area under the title "Optimism is the biology of hope" (Suad, 2015).

Chronic diseases lead to many deaths each year. In addition to the threat to life, patients are exposed to various 
physical and psychological disabilities that affect their life quality negatively (Alonso et al, 2004). Medical standards explain a limited amount of variation in the quality of life outcomes, while psychological factors explain the other disparities, therefore, the quality of life may be severely affected by psychological changes in patients with diseases that have no effective medical systems to treat or that the effectiveness of treatment is limited (Woolf \& Pfleger, 2003).

Many studies have examined the impact of an individual's optimistic or pessimistic view of health and well-being, and found that those with an optimistic outlook tend to expect a positive life while pessimists tend to expect a negative life outcome (Carver, Scheier \& Segerstrom, 2010; Carver, 1985). Studies have also shown fundamental differences between the way optimists and pessimists view life as affecting their perception of how they cope with problems adapt with it with adversity (Carver, 2010).

The concept of optimism refers to the expectation of the individual that things in life will go well despite some setbacks or failures. The concept of optimism in terms of emotional intelligence is a position that prevents the individual from falling into apathy, loss of hope and frustration in the face of difficult life, optimism also increases human gains if they are realistic optimism. Optimism is a composite of talent with the ability to follow up in the face of failure to success. In this context, Seligman (1995) identified the concept of optimism in the way people attribute to themselves the reasons for their success or failure, the optimist attributes his failure to something that he can change and thus can succeed next time, the pessimistic attributes his failure to permanent qualities they cannot change (Goleman, 2000). These two ways of attributing the causes of failure have profound implications for how people respond to life.

The optimists accept the positions in which they fail and cause them disappointment and then put a plan of action to overcome it and they do not hesitate to seek advice from others, the failure or setback for them a position can be cured and overcome it, in contrast, the pessimists, they think they are unable to do anything that can improve things next time therefore do nothing for the problem, they attribute their failure to a personal deficit which will continue to cause them continued failure (Khalil, 2008).

Optimism is defined as a look toward the future that makes the individual expect the best, wait for the positive things and rule out otherwise (Ansari, 1998).

As defined by Mekhemer and Abdul-Mu'ti (2000) as a characteristic that makes the individual and his orientation positive towards life in general.

Carver \& Scherier (2010) also defined it as a positive lifestyle, belief in the possibility of fulfilling desires in the future, and that he is willing to expect the occurrence of good things and positive and optimistic believes that the future holds the results.

The optimism may come in a negative way, such as "unrealistic optimism". It is meant by the exceptional optimism or optimism that is not justified by introductions or facts, which put the person at risk of ill health. As well as "comparative optimism" is the tendency of the individual to predict the occurrence of good things for him alone without others and his tendency to predict the occurrence of bad things for others and not occur to him (Suad, 2010).

\subsection{Significance of the Study}

The importance of this study stems from the treatment of a social group with chronic renal failure. Because the disease has been increasing in recent times for many reasons and people suffering from this disease have real suffering in their lives because they do not accept their illness, in addition, this study reveals some of the psychological, social and emotional problems of patients with renal failure, as they tend to be isolated from others because they believe that their days are no longer due to the nature of chronic disease.

The importance of this study stems from the fact that it will provide a conceptual framework for the rest of the researchers in previous studies, since this subject has not been addressed in Jordan and the Arab world as far as the researchers know.

This study also provides important results that may benefit hospital staff from medical staff and guidance in the way they deal with patients with renal failure to reach better therapeutic results.

\subsection{The Study Problem and its Questions}

Renal failure is a common disease in Jordan in particular and the Arab world in general, it is a chronic disease, and individuals with renal failure suffer from lifestyle changes as a result of the disease, it is a disease as we mentioned chronic and long-term the patient may not heal from it, which is a life-threatening diseases, therefore, patients suffer from poor mental state and become prone to anxiety and tension and fear of what they will face in 
the future due to serious complications of the disease and the reactions of individuals towards the disease vary, but mostly in the denial and rejection of the disease they deliberately neglect treatment as an expression of their rejection and denial, Ibrahim (1993) states that a great fear may arise in the patient, which, if increased, to enter the patient in a state of depression and isolation, he may feel guilty as the individual feels that the disease is a punishment for the mistakes made in the past, which may enter the patient in a state of frustration.

Optimism and pessimism play an important and decisive role in the improvement or deterioration of the patient's health. Several studies mentioned the effect of optimism on the patient's acceptance of his illness and his response to the doctor's advice and optimism in recovering from the disease or adapting to it, which reflected on the quality of his life and feel a state of improvement and happiness, and conversely, if the patient is pessimistic he will refuse treatment to despair of healing and will enter into a state of depression and frustration reflected on his quality of life prevents him from communicating with others and refused treatment and not follow the directions of the doctor.

Hence, the problem of the study emerged in the detection of the level of optimism and pessimism and its relationship to the quality of life in patients with renal failure in light of the variables, gender and age and the duration of the disease and the level of education of patients, and the problem of study is determined in answer to the following questions:

\subsection{Questions of the Study}

1. What is the level of optimism in patients with renal failure in the government and private hospitals of Irbid?

2. What is the level of pessimism in patients with renal failure in the government and private hospitals of Irbid?

3. What is the level of quality of life in patients with renal failure in the government and private hospitals of Irbid?

4. Are there any statistically significant differences at the level $(\alpha=0.05)$ of optimism and pessimism in patients with renal failure due to gender, age, duration of disease and scientific level of patients?

5. Are there any statistically significant differences at the level $(\alpha=0.05)$ of quality of life with renal failure due to age, marital status, housing and education level of patients?

\subsection{Definitions of Terms}

\subsubsection{Optimism}

Seligman (1995) defined it as an optimistic personality trait as the way an individual interprets his direction towards success and failure in his life. An optimistic individual sees failure as a source of development and success, so he acts and responds effectively. It is defined as the degree obtained by the respondent that is based on the optimism used in this study.

\subsubsection{Pessimism}

It is the individual's perception of things and phenomena around him in a negative way. The pessimist sees failure as a tragedy that cannot be overcome. In this study, it is defined as the degree obtained by the respondent on the pessimism scale used in the study.

\subsubsection{Quality of Life}

It is defined by the World Health Organization (2013) as the individual's perception of a sign in life, the health and happiness of the individual, the satisfaction of his needs and desires, his appreciation of himself in the context of culture and the values in which he lives, and link them to his own goals, expectations, interests and beliefs. The degree to which the respondent obtains is based on the quality of life scale used in this study.

\subsubsection{Renal Failure}

It is an irreversible reduction in kidney function that is life threatening if not treated with dialysis or kidney transplantation, the fifth degree of chronic kidney failure where the ability of the kidney to filter does not exceed $15 \mathrm{ml} / \mathrm{min}$ per 1.73 of the surface of the body (National Kidney Foundation, 2002).

\section{Previous Studies}

A study by Radwan (2001) aimed at determining the nature of the correlation between depression and pessimism on a Saudi sample consisting of (1116) male and female students from secondary and university levels. The results indicated a positive relationship between depression and pessimism with a gender effect on depression in favor of females who were more depressed than males. 
Douglas (2000) studied the gender differences in the depression variable on a sample of secondary students. The average age was (1-16) years, where $\mathrm{N}=(400)$ males and (200) females. The results of the study indicated that the level of depression is higher among the female sample compared to their male counterparts.

Jenifer \& Stephen2002 conducted a study including (114) male students as a control sample and (87) male students as a comparative sample. They ranged in age from (7-12) years, the study aimed to determine the levels and relationship of depression with self-esteem in a sample of students who are characterized by disorders resulting from hyperactivity as well as their attention deficit, and relationship of these disorders and aggression. The most important results indicated in this study is the relationship of adverse correlation between depression and self-esteem and females more self-esteem than males.

Diane et al. (2002) conducted a study aimed to determine the relationship between depression for self-esteem and psychological unity and social support on a sample of mothers of adolescents participating in the new project on parental contributions in the community. The sample of the study included (21) female employee, the main findings of this study were the absence of a significant correlation between depression and self-esteem and a very high percentage of symptoms of depression compared to the rest of women who had a low rate of depression symptoms.

The study of Nan eyetal (2007) aimed to determine the relationship between stress and depression as predictors of optimism and cognitive control. The study included (97) families. The most important findings of the study were that there is an inverse correlation between stress and optimism on the one hand and depression on the other.

Wuerth \& Toto (2005) conducted a study entitled: "Identification and treatment of depression in patients with chronic peritoneal dialysis, the study aimed at estimating the number of patients suffering from depression and trying to provide treatment for them and the study was conducted on the number of (136) patients receiving dialysis. The researchers used a Beck scale for depression, a self-administered questionnaire and the Hamilton Depression Scale. Patients receiving grades 11 and above were referred to a psychiatrist and the number of patients who received 11 or more was 67 patients, the number of patients with clinical depression was 23 and 22 were eligible for antidepressant treatment based on their scores on the Hamilton Depression Scale and during diagnostic interviews. The results of the study found that depression is a widespread prevalence among patients with chronic peritoneal dialysis, and that the scale or list of Beck Depression is a useful tool to identify depression, and clinical depression can be treated with drugs in this category of patients.

Daneker et al., (2001) conducted a study entitled "Depression and lack of marital satisfaction in patients with kidney failure among their wives or husbands" the aim of the study was to evaluate the relationship between the level of depression of the patient and the psychological state of his wife or husband. The study was applied to a sample consisting of (55) husband in which one of the spouses suffers from treatment with chronic blood washing. Two variables were studied to determine whether they might be related to the level of partner depression and marital satisfaction. These variables are the level of patient depression and the perceived social support of the partner (the other party). Depression was assessed using the BIC Depression List. The results of the study showed that there is a direct correlation between partner depression levels and patient scores on the Beck Depression List, and that there is a major effect (for social support from the other side from the patient's perspective) on partner satisfaction, the wives or husbands of patients with high levels of social support were less likely to suffer from marital stress, and the psychosocial condition of the patient's wife affected the level of the patient's depression.

Bakewell (2002) conducted a study entitled Quality of life in patients with peritoneal dialysis, the deterioration of the condition over time and its association with clinical outcomes. The objective of the study is to determine which key factors affect quality of life, and which aspects of quality of life that change over time, and if there was a correlation between quality of life scales and the clinical outcomes of patients with peritoneal dialysis patients. The study was applied to 88 patients with renal failure who accounted for $70 \%$ of those treated with washing, who are enrolled in longitudinal studies on the suitability of washing, nutrition and quality of life. The sample included 35 Asian Indians and 53 white Europeans, all of whom had diabetes. They were selected after being treated with washing for about three months. Their demographic data were collected; data on the disease were recorded at intervals between the first and the six months. The data addressed the adequacy of treatment, nutritional status and quality of life Using (SF-KDQOL) scale, hospital entry records and changes in the treatment model. The results of the study showed that the most important characteristics that were associated with poor quality after life quality is a type property (males in particular), and Asian ethnicity, and poor nutritional status according to the overall self-assessment scale (SGA). the quality of life included aspects of 
physical health, mental health, and issues related to kidney disease and patient satisfaction. The nineteen health fields were measured and their association with months of renal replacement, social deprivation and the use of albumin serum, and found that the quality of life has deteriorated at a steady rate during the study period, and the most prominent changes that have occurred to the general aspects of symptoms and health problems and the burden of kidney disease and emotional state and patient satisfaction, and related dimensions of the hospital deterioration of quality of life. The final conclusions of the study were further research into the effects of interventions aimed at increasing emotional and social support.

\section{Methodology of the Study}

\subsection{Population of the Study}

The population of this study consisted of all patients with renal failure in the government and private hospitals in Irbid during the 2018 year

\subsection{Study Sample}

The study sample consisted of (93) Patients with renal failure, who were randomly selected from the study population. Tables (2-3) show the descriptive statistics of the Socio-Demographics and Health Profile.

Table 1. Descriptive statistics of the Socio-Demographics

\begin{tabular}{|c|c|c|c|}
\hline Variable & Group & Frequency & Percentage \\
\hline \multirow[t]{3}{*}{ Gender } & Male & 49 & 52.7 \\
\hline & Female & 44 & 47.3 \\
\hline & Total & 93 & 100.0 \\
\hline \multirow[t]{8}{*}{ Age } & $10-20$ years & 5 & 5.4 \\
\hline & $21-30$ years & 21 & 22.6 \\
\hline & $31-40$ years & 27 & 29.0 \\
\hline & $41-50$ years & 18 & 19.3 \\
\hline & $51-60$ years & 16 & 17.2 \\
\hline & 61 years and more & 6 & 6.5 \\
\hline & Total & 93 & 100.0 \\
\hline & Married & 67 & 72.0 \\
\hline \multirow[t]{4}{*}{ Marital Status } & Single & 25 & 26.9 \\
\hline & Divorced & 1 & 1.1 \\
\hline & Widowed & 0 & 0.00 \\
\hline & Total & 93 & 100.0 \\
\hline \multirow[t]{4}{*}{ Housing } & Alone & 9 & 9.8 \\
\hline & With spouse & 26 & 28.0 \\
\hline & Relative & 58 & 62.2 \\
\hline & Total & 93 & 100.0 \\
\hline \multirow[t]{7}{*}{ Education Level } & Graduate school & 7 & 7.5 \\
\hline & $\mathrm{BA}$ or BS & 12 & 12.9 \\
\hline & High School Diploma & 30 & 32.2 \\
\hline & Preparatory school & 27 & 29.0 \\
\hline & Elementary school & 13 & 14.0 \\
\hline & Unable to read or write & 4 & 4.3 \\
\hline & Total & 93 & 100.0 \\
\hline \multirow[t]{3}{*}{ Family income } & $\geq 500$ & 57 & 61.3 \\
\hline & $<500$ & 36 & 38.7 \\
\hline & Total & 93 & 100.0 \\
\hline \multirow[t]{3}{*}{ Medical Insurance } & Yes & 83 & 89.2 \\
\hline & No & 10 & 10.8 \\
\hline & Total & 93 & 100.0 \\
\hline \multirow[t]{3}{*}{ Origin } & Urban & 63 & 67.7 \\
\hline & Rural & 30 & 32.2 \\
\hline & Total & 93 & 100.0 \\
\hline
\end{tabular}


Table (1) shows the following:

- The number of males was (49) (52.7\%) of the sample, while the number of female was (44) which represents $(47.3 \%)$ of the study sample.

- The highest percentage of the age was (29.0\%) for (31-40 years), while the lowest percentage was $(5.4 \%)$ for (10 - 20 years).

- The highest percentage of the marital status in the study sample was (71.7\%) for (married), while the lowest percentage was (1.1\%) for (Divorced).

- The highest percentage of the housing in the study sample was $(62.2 \%)$ for (relative), while the lowest percentage was $(9.8 \%)$ for (alone).

- The highest percentage of the educational level in the study sample was (32.2\%) for (High school diploma), while the lowest percentage was $(4.3 \%)$ for (unable to read or write).

- The number of sample members whose income is greater than (500) was (57) by a percentage of (61.3\%), while the number of those whose income less than (500) was (36) by a percentage of (38.7\%).

- The number of sample members who have medical insurance in study was (83) by a percentage of $(89.2 \%)$, while those who do not have medical insurance was (10) by a percentage $(10.8 \%)$.

- The number of the sample members who are from urban origin was (63) with a percentage $(67.7 \%)$, while those who are from rural origin was (30) with a percentage (32.2\%).

Table 2. Descriptive statistics of the Clinical factors

\begin{tabular}{llll}
\hline Variable & Group & Frequency & Percentage \\
\hline Date of Diagnosis & 2010 and less & 14 & 15.0 \\
& $2011-2015$ & 39 & 42.0 \\
& 2016 and more & 40 & 43.0 \\
Etiology of Renal Failure & Total & 93 & 100.0 \\
& Hypertension & 28 & 30.1 \\
& Diabetes mellitus & 27 & 29.0 \\
& Glomerulonephritis & 2 & 2.2 \\
Frequency of dialysis & Other & 22 & 23.7 \\
& Unknown & 14 & 15.0 \\
& Total & 93 & 100.0 \\
& Once a week & 8 & 8.6 \\
Time length of dialysis & Twice a week & 20 & 21.5 \\
& 3 times a week & 65 & 69.9 \\
& Total & 93 & 100.0 \\
& $<4$ hours & 80 & 86.0 \\
& 4- 5 hours & 13 & 14.0 \\
& 6-8 hours & 0 & 0.00 \\
& Total & 93 & 100.0 \\
& & &
\end{tabular}

Table (2) shows the following:

- The highest percentage of the date of diagnosis reached (43.0\%) for (2016 and more), while the lowest percentage reached (15.0\%) for (2010 and less).

- The highest percentage of the etiology of renal failure in the study sample reached $(30.1 \%)$ for (hypertension), while the lowest percentage reached (2.2\%) for (glomerulonephritis).

- The highest percentage of the frequency of dialysis in the study sample (69.9\%) for (3 times a week), while the lowest percentage reached (8.6\%) for (once a week).

- The highest percentage of the time length of dialysis in the study sample reached $(86.0 \%)$ for $(<4$ hours), while the lowest percentage reached $(0.0 \%)$ for (6-8 hours). 


\subsection{Study Tools}

The researcher used the following scales:

\subsubsection{Optimism and pessimism scale}

\subsubsection{Quality of life scale}

\subsubsection{Optimism and Pessimism Scale}

The researcher prepared the scale of optimism and pessimism by reference to the related psychological literature and using some of optimism and pessimism scales that has been used in different environments, among them: The Arab List of optimism and pessimism. Prepared by: Abdo Al-Humiri(2005) Life-orientation scale by Al-Ansari (2001a) and unrealistic optimism Al - Ansari (2001B) Life - orientation scale prepared by Carver and Schreier (2003).

This step resulted in the formulation of 15 paragraphs for optimism and pessimism. In the formulation of the vocabulary of optimism and pessimism, the clarity and accuracy of the words used in the formulation of the vocabulary were taken into consideration. The instructions have been formulated to answer as follows (Strongly agree - Agree - Neutral - disagree - Strongly disagree) and got the scores (5-4-3-2-1). High score indicates high optimism and low degree of low optimism, The pessimism scale was set, and the high score on the pessimistic scale indicates high pessimism while the low score indicates a low pessimism.

\subsubsection{Validity and Reliability of the Scale}

\subsection{Arbitrators' Validity}

The scales of optimism and pessimism were presented to a group of psychology professors at Al Balqa Applied University; this resulted in the amendment of some paragraphs and the deletion of others, and the scale includes (10) paragraph to measure optimism and (10) to measure the pessimism in its initial form. The scale was then presented to a sample of (20) students to make sure that the scores of optimism and pessimism were clear and to determine the time taken to answer. This step resulted in the exclusion of (5) paragraphs of optimism and pessimism to the number of paragraphs (7), and (8) for pessimism.

\subsubsection{Reliability of the Scale}

The reliability of the scale of optimism and pessimism was determined by calculating Cronbach Alpha coefficient of and Spearman Brown. The reliability coefficient of the optimism and pessimism scales using Alfa Cronbach and Spearman Brown is high, indicating the reliability of the scale, and the researcher verified the reliability of the scale by re-application on a sample of the study community and outside the core sample consisted of (20) students, the reliability coefficient of optimism was (87.0) and pessimism (84.0).

\subsubsection{Quality of Life Scale}

Quality of life Scale: To determine the quality of life in patients with renal failure, the author reviewed the abbreviated quality of life scale (Quality of life Scale-BRIEF-WHOQQL)prepared by The World Health Organization (WHO), The World Health Organization, started with Global Quality of Life Project and established a global scale of 100 paragraphs (WHOQOL- 100) within six domains: physical, psychological, Social relations or the environment and the level of independence and spiritual health, which was later reduced to (WHOQOL-Bref) which consists of (26) paragraph within four areas: physical health, psychological, social relations, and the environment, and this scale is used with ordinary people and patients such as cancer patients, diabetes, heart and hypertension, The statistical characteristics of this scale were estimated on heterogeneous samples of patients and healthy people across 23 WHO centres in different countries. The results of statistical analyses showed that the internal consistency value of the scales ranged from (68.0 to 82.0), satisfactory and function, which means that the scale is characterized by very high psychometric characteristics.

\subsubsection{Validity of the Scale}

Content validity: it was verified by presenting it to a group of (12) arbitrators, professors from Al Balqa Applied University, with experience and specialization in the fields of psychological counselling and educational psychology. They were asked to give an opinion on the accuracy and correctness of the content of the tool, in terms of the integrity of translation, clarity of paragraphs and language formulation, and its relevance to measure what it was put for it, and add, modify or delete what they deem appropriate on the domains or paragraphs. In the light of the arbitrators' opinions, amendments were made to the Quality of life scale, some paragraphs have been redrafted to become more clear and direct. All paragraphs of the scale have been preserved, and any of the four 
domain paragraphs have not been deleted, and the scale was adopted in the acceptance of paragraphs where each paragraph has to get the approval of $(80 \%)$ of the arbitrators to retain it.

\subsubsection{Reliability of the Scale}

The reliability of the study tool was verified using the test/retest method by applying the scale to a sample of (20) patients with renal failure outside the targeted study sample within a period of time (15) days. the reliability was verified also through the internal consistency method using the formula of (Cronbach Alpha).

\section{Results and Discussion}

Results related to the first question: What is the level of optimism in patients with renal failure in the government and private hospitals of Irbid?

To answer this question, means and standard deviations for the answers of the study sample on the optimism scale were extracted; Table (3) clarifies this

Table 3. Means and standard deviations for level optimism items ranked in descending order

\begin{tabular}{llllll}
\hline $\mathbf{N}$ & Item & Mean & St. deviation & Rank & Level \\
\hline $\mathbf{5}$ & Whenever there's a will, there's a way out & 3.602 & 0.934 & 1 & Medium \\
$\mathbf{4}$ & When I undertake something new, I expect to succeed. & 3.591 & 0.947 & 2 & Medium \\
$\mathbf{1}$ & At difficult times, I usually expect the best & 3.548 & 0.961 & 3 & Medium \\
$\mathbf{7}$ & I rarely count on good things happening to me & 3.505 & 0.928 & 4 & Medium \\
$\mathbf{6}$ & In general, things turn out alright at the end & 3.473 & 0.951 & 5 & Medium \\
$\mathbf{2}$ & I always look at the bright side of things & 3.366 & 1.140 & 6 & Medium \\
$\mathbf{3}$ & I am always optimistic about my future. & 3.075 & 1.209 & 7 & Medium \\
& Total & 3.452 & 0.639 & \multicolumn{2}{c}{ Medium }
\end{tabular}

Table (3) shows the means for optimism scale ranged from (3.602-3.075) by medium degrees. The highest mean is for item (5) "whenever there's a will, there's a way out", then followed by (3.591) for item (4) "When I undertake something new, I expect to succeed.", while the lowest mean is for item (3) "I am always optimistic about my future". The mean for optimism scale as a whole is (3.452) by medium degree.

Results related to the second question: What is the level of pessimism in patients with renal failure in the government and private hospitals of Irbid?

To answer this question, means and standard deviations for the answers of the study sample on the pessimism scale were extracted. Table (4) shows the results.

Table 4. Means and standard deviations for level pessimism items ranked in descending order

\begin{tabular}{|c|c|c|c|c|c|}
\hline $\mathbf{N}$ & Item & Mean & St. deviation & Rank & Level \\
\hline 4 & I hardly ever expect things to come on my way. & 4.086 & 0.985 & 1 & High \\
\hline 1 & $\begin{array}{l}\text { It is better not to get your hopes too high since you will } \\
\text { probably be disappointed }\end{array}$ & 3.882 & 1.131 & 2 & High \\
\hline 3 & If I am fated to something wrong, surely it will take place & 3.763 & 1.067 & 3 & High \\
\hline 5 & Things never work out the way I want them to & 3.667 & 1.014 & 4 & High \\
\hline 7 & $\begin{array}{l}\text { It is better to expect defeat, in order not to hit so hard } \\
\text { when it comes }\end{array}$ & 3.581 & 0.993 & 5 & Medium \\
\hline 2 & Rarely do I expect good things to happen & 3.516 & 1.069 & 6 & Medium \\
\hline 6 & $\begin{array}{l}\text { If I make a decision on my own, I pretty much count on } \\
\text { the fact that it will turn out to be a poor one }\end{array}$ & 3.204 & 0.951 & 7 & Medium \\
\hline 8 & $\begin{array}{l}\text { Give me } 50 \backslash 50 \text { odds and I will choose the wrong answer } \\
\text { every time. }\end{array}$ & 3.118 & 0.965 & 8 & Medium \\
\hline & Total & 3.602 & 0.514 & \multicolumn{2}{|l|}{ Medium } \\
\hline
\end{tabular}


Table (4) shows the means for pessimism scale are ranged from (4.086-3.118) by high and medium degrees. The highest mean is for item (4) "I hardly ever expect things to come on my way" by a high degree, then followed by (3.882) for item (1) "It is better not to get your hopes too high since you will probably be disappointed". The lowest mean is for item (8) "Give me 50\50 odds and I will choose the wrong answer every time". The mean for pessimism scale as a whole is (3.602) by medium degree.

Results related to the third question: What is the level of quality of life in patients with renal failure in the government and private hospitals of Irbid?

To answer this question, means and standard deviations for the answers of the study sample on the quality of Life Scale. Table (5) explains this.

Table 5. Means and standard deviations for quality of life scale items ranked in descending order

\begin{tabular}{|c|c|c|c|c|c|}
\hline $\mathbf{N}$ & Item & Mean & St. deviation & Rank & Level \\
\hline 5 & $\begin{array}{l}\text { To what extent does any connection to a spiritual } \\
\text { being help you to get through hard time? }\end{array}$ & 4.054 & 0.937 & 1 & High \\
\hline 12 & How dependent are you on medications? & 4.000 & 1.198 & 2 & High \\
\hline 8 & $\begin{array}{l}\text { To what extent does any connection to a spiritual } \\
\text { being help you to tolerate stress? }\end{array}$ & 3.935 & 0.805 & 3 & High \\
\hline 20 & $\begin{array}{l}\text { To what extent does any connection to a spiritual } \\
\text { being provide you with comfortl reassurance? }\end{array}$ & 3.903 & 1.074 & 4 & High \\
\hline 4 & Do your personal beliefs give meaning to your life? & 3.892 & 1.047 & 5 & High \\
\hline 14 & $\begin{array}{l}\text { To what extent do your personal beliefs give you the } \\
\text { strength to face difficulties? }\end{array}$ & 3.839 & 0.912 & 6 & High \\
\hline 15 & $\begin{array}{l}\text { To what extent does any connection to a spiritual } \\
\text { being help you to understand others? }\end{array}$ & 3.785 & 1.326 & 7 & High \\
\hline 19 & $\begin{array}{l}\text { To what extent do your personal beliefs help you to } \\
\text { understand difficulties in life? }\end{array}$ & 3.774 & 0.968 & 8 & High \\
\hline 3 & Are you able to work & 3.581 & 1.362 & 9 & Medium \\
\hline 17 & $\begin{array}{l}\text { Do you get the kind of support from others that you } \\
\text { need? }\end{array}$ & 3.570 & 0.993 & 10 & Medium \\
\hline 6 & How positive do you feel about the future? & 3.548 & 1.048 & 11 & Medium \\
\hline 10 & Do you feel able to carry out your duties? & 3.538 & 1.175 & 12 & Medium \\
\hline 2 & Do you have enough energy for everyday life? & 3.516 & 1.069 & 13 & Medium \\
\hline 7 & $\begin{array}{l}\text { To what extent are you able to carry out your daily } \\
\text { activities? }\end{array}$ & 3.505 & 1.080 & 14 & Medium \\
\hline 11 & How much do you value yourself? & 3.495 & 1.119 & 15 & Medium \\
\hline 18 & How would you rate your ability to work? & 3.452 & 1.184 & 16 & Medium \\
\hline 9 & $\begin{array}{l}\text { To what extent do you feel your life to be } \\
\text { meaningful? }\end{array}$ & 3.366 & 1.008 & 17 & Medium \\
\hline 13 & How satisfied are you about your capacity to work? & 3.355 & 1.139 & 18 & Medium \\
\hline 1 & $\begin{array}{l}\text { How much do you experience positive feelings in } \\
\text { your life? }\end{array}$ & 3.344 & 0.866 & 19 & Medium \\
\hline 23 & $\begin{array}{l}\text { To what extent can you count on your friends when } \\
\text { you need them? }\end{array}$ & 3.215 & 0.987 & 20 & Medium \\
\hline 21 & How much do you enjoy life? & 3.086 & 1.148 & 21 & Medium \\
\hline 22 & To what extent do you find meaning in life? & 3.043 & 0.988 & 22 & Medium \\
\hline \multirow[t]{2}{*}{16} & Do you feel inhibited by your look? & 2.957 & 1.215 & 23 & Medium \\
\hline & Quality of life scale as a whole & 3.554 & 0.524 & \multicolumn{2}{|c|}{ Medium } \\
\hline
\end{tabular}

Table (5) shows the means for quality of life scale ranged from (4.054-2.957) by high and medium degree. The highest mean is for item (5) "To what extent does any connection to a spiritual being help you to get through hard time?" (4.054) followed by item (12) "How dependent are you on medications?" (4.000), while the lowest 
mean is for item (16) "Do you feel inhibited by your look?" (2.957). The mean for quality of life scale as a whole is (3.554) with a medium degree.

Table 6. The result for Pearson correlation between (optimism scale, pessimism scale, quality of life scale)

\begin{tabular}{|c|c|c|c|c|}
\hline Scale & & $\begin{array}{l}\text { Optimism } \\
\text { scale }\end{array}$ & $\begin{array}{l}\text { Pessimism } \\
\text { scale }\end{array}$ & $\begin{array}{l}\text { Quality of life } \\
\text { scale }\end{array}$ \\
\hline \multirow[t]{3}{*}{ Optimism scale } & Pearson Correlation & 1 & 0.139 & $0.588^{* *}$ \\
\hline & Sig. (2-tailed) & & 0.183 & 0.000 \\
\hline & $\mathrm{N}$ & 93 & 93 & 93 \\
\hline \multirow[t]{3}{*}{ Pessimism scale } & Pearson Correlation & 0.139 & 1 & 0.074 \\
\hline & Sig. (2-tailed) & 0.183 & & 0.482 \\
\hline & $\mathrm{N}$ & 93 & 93 & 93 \\
\hline \multirow{3}{*}{$\begin{array}{l}\text { Quality of life } \\
\text { scale }\end{array}$} & Pearson Correlation & $0.588^{* *}$ & 0.074 & 1 \\
\hline & Sig. (2-tailed) & 0.000 & 0.482 & \\
\hline & $\mathrm{N}$ & 93 & 93 & 93 \\
\hline
\end{tabular}

** Correlation is significant at the $(\alpha \leq 0.01)$

Table 6 shows the following:

- Pearson correlation between optimism and quality of life reached (0.588) which is statistically significant at $(\alpha \leq 0.01)$, indicating a correlation between optimism and quality of life, this relationship is a moderately positive relationship.

- Pearson correlation between optimism and pessimism reached (0.139) and pessimism and quality of life reached $(0.074)$ which are not statistically significant at the level $(\alpha \leq 0.01)$, indicating no correlation between optimism and pessimism, and level of pessimism and quality of life.

Results related to the fourth question: Are there any statistically significant differences at the level $(\alpha=0.05)$ of optimism and Pessimism in patients with renal failure due to gender, age, duration of disease and scientific level of patients?

The results are shown in tables 7,8 and 9 as follows:

Table 7. Result of (T-test) for optimism and pessimism scale according to (gender, family income, medical insurance, and origin) variables

\begin{tabular}{lllllll}
\hline Variable & Scale & Group & Mean & T-value & df & Sig \\
\hline Gender & Optimism & Male & 3.464 & 0.389 & 90 & 0.698 \\
& scale & Female & 3.412 & & & \\
& Pessimism & Male & 3.546 & -1.138 & 90 & 0.258 \\
& scale & Female & 3.669 & & & \\
Family income & Optimism & $501 \geq$ & 3.459 & 0.372 & 90 & 0.710 \\
& scale & $500<$ & 3.409 & & & \\
& Pessimism & $501 \geq$ & 3.634 & 0.708 & 90 & 0.481 \\
& scale & $500<$ & 3.556 & & & \\
Medical & Optimism & Yes & 3.415 & 1.080 & 90 & 0.283 \\
& scale & No & 3.643 & & & \\
& Pessimism & Yes & 3.598 & 0.301 & 90 & 0.764 \\
& scale & No & 3.650 & & & \\
& Optimingm & Urban & 3.353 & -1.927 & 90 & 0.06 \\
& scale & Rural & 3.619 & & & \multirow{2}{*}{0.234} \\
& Pessimism & Urban & 3.558 & -1.198 & 90 & 0.206 \\
& scale & Rural & 3.696 & & & \\
\hline
\end{tabular}


Table (7) shows the T-value for (optimism, pessimism scales) according to (gender, family income, medical insurance and origin). There are no statistically significant differences at the level of significance $(\alpha \leq 0.05)$ in the patients' responses on the optimism and pessimism scales according to (gender, family income, medical insurance and origin)

Table 8. mean according to (age, marital status, housing, and education level) variables

\begin{tabular}{|c|c|c|c|}
\hline \multirow[t]{2}{*}{ Variable } & \multirow[t]{2}{*}{ Group } & Optimism scale & Pessimism scale \\
\hline & & Mean & Mean \\
\hline \multirow[t]{6}{*}{ Age } & $10-20$ year & 3.429 & 3.500 \\
\hline & 21-30 year & 3.537 & 3.685 \\
\hline & $31-40$ year & 3.418 & 3.611 \\
\hline & $41-50$ year & 3.635 & 3.618 \\
\hline & $51-60$ year & 3.223 & 3.625 \\
\hline & 61 year and more & 3.190 & 3.271 \\
\hline \multirow[t]{4}{*}{ Marital Status } & Married & 3.433 & 3.589 \\
\hline & Single & 3.423 & 3.620 \\
\hline & Divorced & 4.286 & 4.125 \\
\hline & Widowed & 0 & 0.00 \\
\hline \multirow[t]{3}{*}{ Housing } & Alone & 3.460 & 3.667 \\
\hline & With spouse & 3.566 & 3.389 \\
\hline & Relative & 3.378 & 3.691 \\
\hline \multirow[t]{6}{*}{ Education Level } & Graduate school & 3.857 & 3.071 \\
\hline & $\mathrm{BA}$ or $\mathrm{BS}$ & 3.726 & 3.677 \\
\hline & High School Diploma & 3.453 & 3.625 \\
\hline & Preparatory school & 3.439 & 3.662 \\
\hline & Elementary school & 3.099 & 3.654 \\
\hline & Unable to read or write & 2.857 & 3.594 \\
\hline
\end{tabular}


Table 9. The result of (One way ANOVA) of optimism and pessimism scale to their (age, marital status, housing, education level)

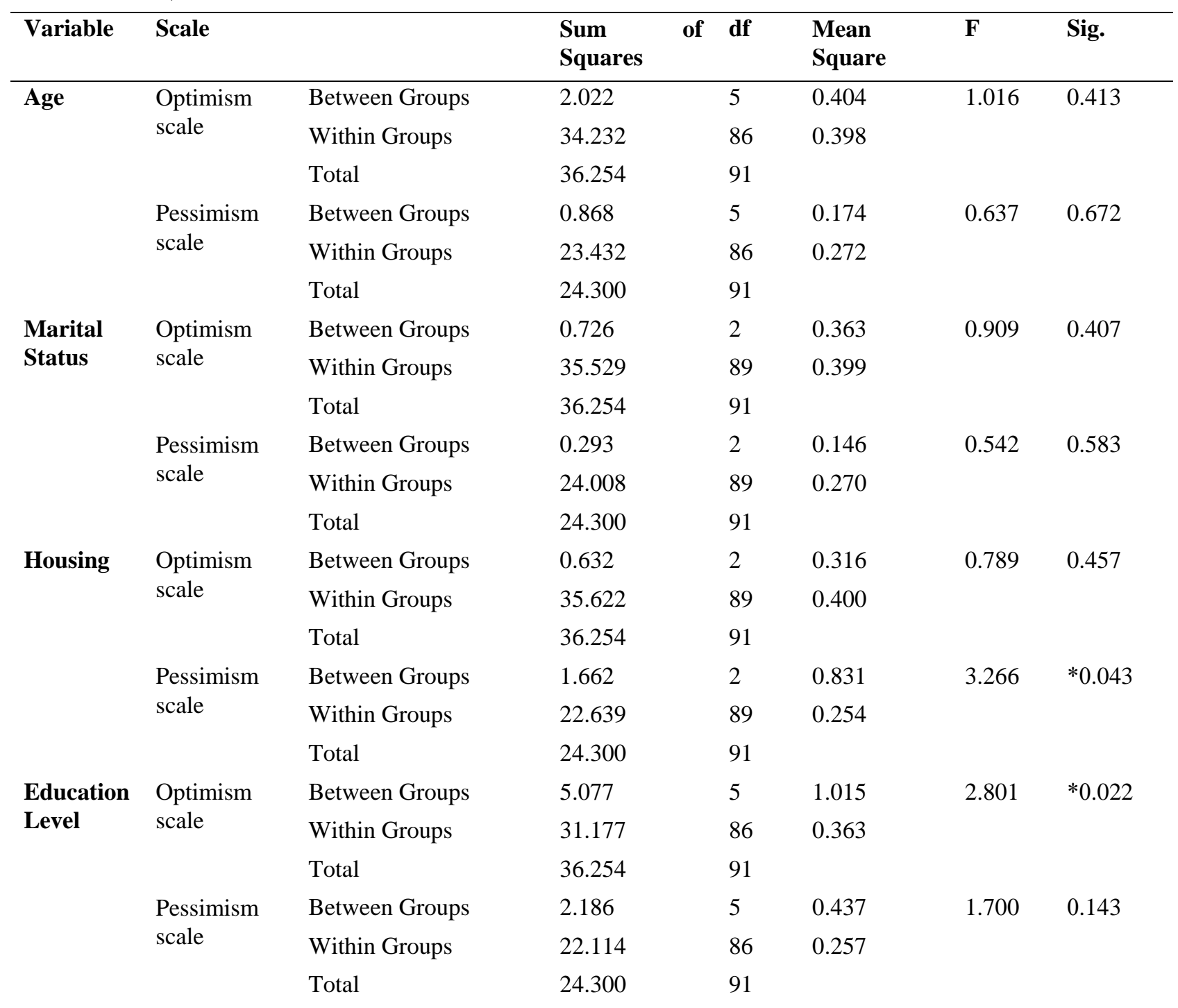

* Statistical is significant at the $(\alpha \leq 0.05)$

Table (9) Shows the following:

- The F-value for (optimism scale) according to (age, marital status and housing) reached (1.016, 0.909, $0.789)$ respectively, showing no statistically significant differences at the level of $(\alpha \leq 0.05)$.

- $\quad$ The F-value for (Pessimism scale) to their (age, marital status and education level) reached (0.637, $0.542,1.700)$, showing no statistically significant differences at the level of $(\alpha \leq 0.05)$.

- $\quad$ The F-value for optimism and pessimism scales to their education level and housing respectively reached (3.266, 2.801), showing a statistically significant differences at the level of $(\alpha \leq 0.05)$.

To find out these differences, the Scheffe test was used to show post comparisons. Tables $(10,11)$ illustrate this:

Table 10. Results of Scheffe test for post comparisons of pessimism scale

\begin{tabular}{llll}
\hline Housing & Alone & With spouse & Relative \\
\hline Alone & & & \\
With spouse & & 0.302 & \\
Relative & & & 3.691
\end{tabular}

Table (10) shows the differences between the housing (with spouse, relative), these differences were in favor of housing (relative) where the mean for this housing is (3.691). 
Table 11. Results of Scheffe test for post comparisons of optimism scale

\begin{tabular}{|c|c|c|c|c|c|c|}
\hline Education level & $\begin{array}{l}\text { Graduat } \\
\text { e school }\end{array}$ & BA or BS & $\begin{array}{l}\text { High } \\
\text { School } \\
\text { Diploma }\end{array}$ & $\begin{array}{l}\text { Preparatory } \\
\text { school }\end{array}$ & $\begin{array}{l}\text { Elementary } \\
\text { school }\end{array}$ & $\begin{array}{l}\text { Unable to } \\
\text { read or write }\end{array}$ \\
\hline Graduate school & 3.857 & & & & & 1.00 \\
\hline \multicolumn{7}{|l|}{ BA or BS } \\
\hline \multicolumn{7}{|c|}{ High School Diploma } \\
\hline \multicolumn{7}{|l|}{ Preparatory school } \\
\hline \multicolumn{7}{|l|}{ Elementary school } \\
\hline $\begin{array}{l}\text { Unable to read or } \\
\text { write }\end{array}$ & & & & & & \\
\hline
\end{tabular}

Table (11) shows the differences between the education level (graduate school, BA or BS, High School Diploma, Preparatory school, Elementary school, unable to read or write), these differences were in favor of education level (graduate school) where the mean for this level is (3.857).

Results related to the fifth question: Are there any statistically significant differences at the level $(\alpha=0.05)$ of quality of life with renal failure due to age, marital status, housing and educational level of patients?

Table 12. The mean values for the quality of life scale by the variables (age, marital status, housing and educational level)

\begin{tabular}{lll}
\hline & Group & Mean \\
\hline Age & 10-20 years & 2.878 \\
& 21-30 years & 3.538 \\
31-40 years & 3.627 \\
& 41-50 years & 3.850 \\
& 51-60 years & 3.380 \\
Marital Status & 61 years and more & 3.362 \\
& Married & 3.612 \\
Housing & Single & 3.390 \\
& Divorced & 3.435 \\
& Widowed & 0.00 \\
Education Level & Alone & 3.556 \\
& With spouse & 3.640 \\
& Relative & 3.507 \\
& Graduate school & 3.584 \\
& BA or BS & 3.721 \\
& High School Diploma & 3.582 \\
& Preparatory school & 3.649 \\
& Elementary school & 3.251 \\
& Unable to read or write & 3.043 \\
\hline
\end{tabular}

Table (12) shows the following:

- The age group (41-50 years) got the highest mean of quality of life which reached (3.850), while the lowest mean was for (10-20 years) with a mean of (2.878).

- Married renal failure patients got the highest mean of quality of life which reached (3.612), while widowed patients got the lowest with a mean of $(0.00)$.

- Renal failure patients who live with spouse got the highest mean of quality of life which reached (3.640), while the lowest mean was for those who live with relatives, it reached (3.507). 
- As for the educational level and its relation to renal failure patients' quality of life, those who hold BA or BS got the highest mean of (3.721), while the lowest mean was for those who are unable to read or write, with a mean of (3.043).

To show the difference between the groups at the quality of life scale, the researcher used (One way ANOVA), table (13) shows the results:

Table 13. The result of applied the test (One way ANOVA) by quality of life scale to their (age, marital status, housing, education level)

\begin{tabular}{|c|c|c|c|c|c|c|c|c|}
\hline Variable & Source of variance & $\begin{array}{l}\text { Sum } \\
\text { Squares }\end{array}$ & of & df & $\begin{array}{l}\text { Mean } \\
\text { Squares }\end{array}$ & of & $\mathbf{F}$ & Sig. \\
\hline \multirow[t]{3}{*}{ Age } & Between Groups & 4.708 & & 5 & 0.942 & & 3.978 & $* 0.003$ \\
\hline & Within Groups & 20.353 & & 86 & 0.237 & & & \\
\hline & Total & 25.061 & & 91 & & & & \\
\hline \multirow{3}{*}{$\begin{array}{l}\text { Marital } \\
\text { Status }\end{array}$} & Between Groups & 0.910 & & 2 & 0.455 & & 1.677 & 0.193 \\
\hline & Within Groups & 24.150 & & 89 & 0.271 & & & \\
\hline & Total & 25.061 & & 91 & & & & \\
\hline \multirow[t]{3}{*}{ Housing } & Between Groups & 0.317 & & 2 & 0.159 & & 0.571 & 0.567 \\
\hline & Within Groups & 24.744 & & 89 & 0.278 & & & \\
\hline & Total & 25.061 & & 91 & & & & \\
\hline \multirow{3}{*}{$\begin{array}{l}\text { Education } \\
\text { Level }\end{array}$} & Between Groups & 2.842 & & 5 & 0.568 & & 2.200 & 0.062 \\
\hline & Within Groups & 22.219 & & 86 & 0.258 & & & \\
\hline & Total & 25.061 & & 91 & & & & \\
\hline
\end{tabular}

* Statistically significant at the level $(\alpha \leq 0.05)$

Table (13) shows the following:

- The F-value for (quality of life scale) according to (marital status, housing and education level) reached $(1.677,0.571,2.200)$ respectively, which is not statistically significant at the level $(\alpha \leq 0.05)$.

- The F-value for quality of life scales to their age reached (3.978) which is statistically significant at the level $(\alpha \leq 0.05)$.

\section{Recommendations}

In light of the results, the researcher recommends the following:

- Encourage further studies on and support for the conditions surrounding patients and disease.

- The establishments of more dialysis units in hospitals near the patient's residence so that the patient does not have to bear the extra effort and the cost of transportation.

- The work of information programs to educate citizens on how to prevent renal failure and how to prevent it.

- The need for a psychologist and social specialist for dialysis units.

- Training the nursing staff on the skills of renal surgeries and how to deal with patients to overcome their psychological problems.

- Disbursement of monthly pensions for each patient, since the patient of renal failure requires a large expenditure to provide for his needs.

- Follow-up of chronic diseases leading to kidney failure.

- The establishment of associations of friends of kidney patients to serve and solve the problems of these patients.

- To provide the necessary medication for these patients and overcome the interruption of medicines needed by the patient, as well as providing the necessary blood for them.

- Conducting seminars in the hospital to educate families of patients about the psychological conditions of the patient and how to deal with them. 


\section{References}

Abdul Karim, E. (2010). Optimism and Relation Toward the Life of Girls of the College of Education for Girls. Journal of Educational and Psychological Research, No. (26) (27), Baghdad.

Ansari, B. (1998). Optimism, pessimism, concept, measurement and related issues, Kuwait University, Scientific Publishing Council, Committee for Arabization, Distribution and Publishing.

Alonso, J.; Ferrer, M.; Gandek, B; Ware, E.; Aaronson, N.; Mosconi, P.; Rasmussen, N. (5004). Health - related quality of life associated with chronic conditions in eight countries: results from the international quality of life assessment ( IQLA) project. Quality of life research, 13(2), 283-298.

Bakewell, A. B. (2002). Quality of life in peritoneal dialysis patients, Decline over time and association with clinical outcomes. journal Kidney, 61(1), 123-128.

Carver, C.; Scheier, M. \& Segerstorm, S. (2010). Optimism Clinical psychology Review, 30(7), 879-889. https://doi.org/10.1016/j.cpr.2010.01.006

Daneker, D. Blackburn, itwaddle,v,\& Burns, D.(2001). Depression and marital dissatisfaction in patient with end-stage renal disease and in their spouses, Departments of Psychology and Medicine, George Washington University, Washington, USA,Am. Journal Kidney-Dis, 38(4).

Golman, D. (2000). Emotional intelligence, translation of Leila Jabali, No. 262, October, the world of knowledge.

Ibrahim, M. (1993). Sugar: spleen and its complications and treatment. Cairo: Al Ahram Center for Translation and Publishing.

Khalil, A. (2008). Emotional intelligence and relation to optimism - pessimism in a sample of students of the Faculty of Education and Science for Girls, Journal of Educational and Psychological Research, College of Education for Girls. University of Baghdad, Issue (20).

Mkhaimer, H. \& Abdelmatti, M. (2000). Optimism and pessimism and its relationship to a number of psychological variables in a sample of students of the University. Journal of Psychological and Social Studies, Faculty of Education, Helwan University, 6(3).

Nabil, B. \& Shu'ail, Y. (2014). Optimism and pessimism and its relationship to the control centre and methods of dealing with pressure. Journal of the generation of human and social sciences, No. 2, Algeria.

Radwan, S. (2001). Variants. Journal of Psychology, 49(15).

Scheier,M. \& Bridges, M.(1995). Person variables and health: personality predispositions and psychological states as shared determinants for disease. Psychosomatic medicine, 57, 255-268. https://doi.org/10.1097/00006842-199505000-00007

Seligman, M. (1995). the optimistic cgild. Newyork; Houghton Mifflin.

Woolf, A. \& Pfleger, B. (2003). Burden of major musculoskeletal conditions. Bulletin of the world health organization, $81(9), 646-656$.

World Health Organization. (2013). Health Report: Comprehensive Coverage Research, Retrieved on 10 November, 2018 from http://www.who.int

World Health Organization. (2015). Diabetic, Newspaper No. 312, Retrieved on 22 November, from the website, http://www.who.int

Wuerth, D.Toto,H. (2001). Identification and treatment of depression in a cohort of patients maintained on chronic peritoneal dialysis. New haven capd, New haven, USA, Am-J-Kidney-Dis, 37(5). https://doi.org/10.1016/S0272-6386(05)80018-6

\section{Copyrights}

Copyright for this article is retained by the author(s), with first publication rights granted to the journal.

This is an open-access article distributed under the terms and conditions of the Creative Commons Attribution license (http://creativecommons.org/licenses/by/4.0/). 